\title{
Properties of felodipine-poly(vinylpyrrolidone) solid dispersion films and the impact of solvents
}

\author{
Krit Suknuntha $^{\mathrm{a}}$, David S. Jones ${ }^{\mathrm{b}}$, Vimon Tantishaiyakul ${ }^{\mathrm{a}, *}$ \\ a Drug Delivery System Excellence Centre and Department of Pharmaceutical Chemistry, \\ Faculty of Pharmaceutical Sciences, Prince of Songkla University, Hat-Yai, Songkhla 90112 Thailand \\ b School of Pharmacy, The Queen's University of Belfast, Medical Biology Centre, 97, Lisburn Road, Belfast, \\ BT9 7BL, United Kingdom
}

${ }^{*}$ Corresponding author, e-mail: vimon.t@psu.ac.th

Received 30 Nov 2011

Accepted 8 May 2012

\begin{abstract}
Solid dispersions of felodipine in polyvinylpyrrolidone (PVP) K90 films were prepared by a solvent evaporation method using various volume ratios of dichloromethane (DM) and ethanol (E). Compared to the others, the solubility parameter of the binary mixtures of DM/E at $5 / 5$ was most close to the solubility parameter of PVP. DSC analysis revealed a single glass transition temperature $\left(T_{\mathrm{g}}\right)$ of the felodipine/PVP films, suggesting that felodipine and PVP were miscible. As indicated by DSC and dynamic mechanical analysis, the $T_{\mathrm{g}}$ of the felodipine/PVP film prepared by using a $\mathrm{DM} / \mathrm{E}$ of $5 / 5$ was higher than those prepared using other DM/E ratios. This high $T_{\mathrm{g}}$ could reflect the high rigidity of this felodipine/PVP film and a high interaction between felodipine and PVP. Using this DM/E ratio, which is a good solvent for this system, the PVP chain elongation could be promoted and provided for a better interaction with felodipine. This strong interaction accounts for the felodipine/PVP film rigidity. Furthermore, according to the texture analysis, the felodipine/PVP film prepared by a DM/E of 5/5 gave the highest Young's modulus and indicated a high polymer chain rigidity. FTIR indicated an interaction of PVP and felodipine. According to the PXRD, all felodipine/PVP films were in the amorphous state and this amorphous state remained for more than 2 months. Thus a film prepared by a DM/E of 5/5 showed the highest stability of its amorphous state after being kept for 2 months.
\end{abstract}

KEYWORDS: glass transition temperature, solubility parameter, solvent evaporation

\section{INTRODUCTION}

Drug bioavailability depends on the solubility and dissolution rate. Enhancement of solubility and the dissolution characteristics of a poorly water-soluble drug is important in improving oral bioavailability ${ }^{1}$. Various approaches have been used to enhance solubility and dissolution rate such as salt formation, particle size reduction, inclusion complexes with cyclodextrin, and solid dispersion ${ }^{1,2}$. Solid dispersion, a simple method used to increase the dissolution rate, consist of the dispersion of a drug within an amorphous or crystalline generally hydrophilic matrix/carrier. If a drug can be molecularly dispersed in an amorphous carrier such as polyvinylpyrrolidone (PVP) or in a crystalline carrier such as $\mathrm{PEG}^{3}$, the drug itself can be in an amorphous form. For example, amorphous ritonavir can be prepared by solid dispersions using PEG 8000 as a carrier ${ }^{3}$. Amorphous solid dispersions of drugs substantially increases in the dissolution rate of the drugs, faster than their crystalline form ${ }^{4}$. A major disadvantage of an amorphous solid is that it has a high potential energy state compared to the crystalline form, and may crystallize. The mechanisms inhibiting crystallization relate to the extent of interaction between a drug and a polymer ${ }^{5}$. Intermolecular interactions between drug molecules and carriers that result in solid dispersions can more or less stabilize the amorphous form of the drug and significantly delay the onset of crystallization ${ }^{6-9}$. Thus selecting a carrier is important to inhibit drug crystallization.

The solubility parameter is widely used to describe the cohesive forces within materials. It is also used to describe many physical properties of a material and can help to predict interactions between a drug and polymer ${ }^{10}$. Hence the solubility parameter is a useful tool for selecting an appropriate carrier ${ }^{10}$. The solubility parameter of the drug and the carrier should be close to each other to obtain strong intermolecular interactions and miscibility. In this study, felodipine was selected as a model drug. It is a calcium channel antagonist used in the treatment of hypertension. Felodipine is classified in the Biopharmaceutical Classification System as a class II drug with low solubility 
and high permeability. The solubility parameter of felodipine obtained from MOLECULAR MODELLING PRO PLUS software is $23.1 \mathrm{MPa}^{1 / 2}$. PVP, a common drug excipient, has been extensively used for solid dispersion preparations due to its ability to interact with a drug molecule and convert crystal forms of drugs to amorphous forms ${ }^{1,2}$. Furthermore, the solubility parameter of PVP is approximately $22.2^{10,11}$ which is close to that of felodipine. Accordingly, PVP was selected as a carrier for the solid dispersion of felodipine.

Solid dispersions may be prepared by various methods such as hot melt extrusion/fusion, solvent evaporation, or spray drying process ${ }^{4,12,13}$. A solid dispersion of felodipine and PVP has been prepared previously by solvent evaporation from ethanol or a mixture of solvents ${ }^{14-16}$. In this study, a solvent evaporation method was used to investigate the influence of the solubility parameter of solvents on the physical properties of the solid dispersion. As previously reported, the solvent used for preparation of a solid dispersion preparation may be categorized as either a good solvent or poor solvent ${ }^{13,17}$. A good solvent will have a solubility parameter value similar to the carrier or a polymer. A good solvent can promote chain elongation of the polymer upon evaporation of the solvent. Consequently, the chain conformation of the polymer will increase resulting in an enhanced molecular interaction between the drug and polymer. In a poor solvent, polymer chains will be compact and in a coil shape causing low molecular interactions between a drug and a polymer. In addition, a good solvent might be obtained by mixing suitable proportions of different solvents to meet the required solubility parameter value. Then, the solvents could enhance molecular interaction between drug and polymer ${ }^{17}$.

In this study, solid dispersions of felodipine and PVP (Fig. 1) were prepared by the film casting method. The effects of the solubility parameter of solvents on the films were studied using various proportions of binary mixtures of dichloromethane (DM) and ethanol (E). The glass transition temperature $\left(T_{\mathrm{g}}\right)$ of the films that reflected the stability of the solid dispersions as a function of temperature were evaluated using differential scanning calorimetry (DSC) and dynamic mechanical analysis (DMA). Young's modulus of felodipine/PVP films were examined using Texture analysis. Moreover, the molecular interactions of felodipine and PVP were determined by Fourier transform infrared spectroscopy and crystallization of felodipine was observed by powder X-ray diffraction (PXRD).

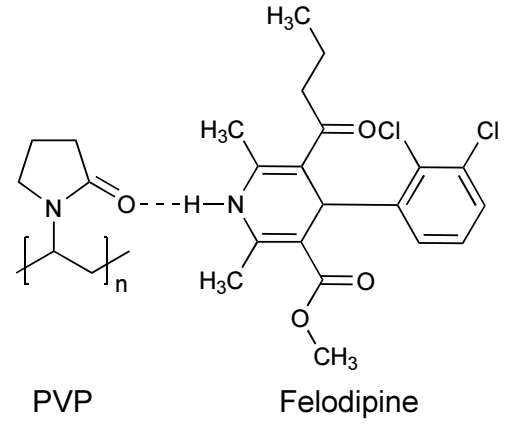

Fig. 1 The chemical structures of PVP and felodipine and the hydrogen bonding interaction between PVP and felodipine.

\section{MATERIALS AND METHODS}

Felodipine was purchased from Molekula (Shaftesbury, UK), PVP K90 (Mw 360 000) was from Fluka (Buchs, USA). DM and $\mathrm{E}$ were of analytical grade.

\section{Film preparation}

Various binary mixtures of $\mathrm{DM} / \mathrm{E}$ were prepared at volume ratios of 9/1, 7/3, 5/5, 3/7, and 1/9. PVP films with $10 \%$ felodipine loading were prepared by dissolving $0.9 \mathrm{~g}$ of PVP K90 and $0.1 \mathrm{~g}$ of felodipine in $10 \mathrm{ml}$ of the solvent mixtures in the $50 \mathrm{ml}$ conical tube by mechanical shaking until all materials were completely dissolved. The solutions $(10 \mathrm{ml})$ were cast on an $8 \times 8 \mathrm{~cm}$ film mould which was fixed onto the surface of a weighing boat with glue. The mould was covered with another weighing boat to delay evaporation of the solvent at room temperature. The dried samples were left at room temperature for another $12 \mathrm{~h}$ to ensure removal of all residual solvents. The thickness of the films was measured using a micrometer (Mitutoyo, Japan).

\section{The solubility parameter of felodipine, PVP, and solvent}

The solubility parameter of felodipine was calculated using Molecular Modelling Pro Plus software for windows (ChemSW) according to $(1)^{18}$. The solubility parameter for PVP, obtained from different sources, were averaged ${ }^{10,11}$. The solubility parameters of binary mixtures of DM and E were calculated using (1) and (2) ${ }^{19,20 \text { : }}$

$$
\begin{gathered}
\delta_{\mathrm{T}}=\left(\delta_{\mathrm{d}}^{2}+\delta_{\mathrm{p}}^{2}+\delta_{\mathrm{h}}^{2}\right)^{1 / 2} \\
\delta_{\text {mixture }}=\Phi_{1} \delta_{1}+\Phi_{2} \delta_{2},
\end{gathered}
$$

where $\delta_{\mathrm{T}}, \delta_{\mathrm{d}}, \delta_{\mathrm{p}}$, and $\delta_{\mathrm{h}}$ are a total solubility parameter, non-polar interaction, polar interaction, and 
hydrogen-bonding component, respectively. In addition, $\delta_{1}$ and $\delta_{2}$ are solubility parameters for each solvent and $\Phi$ is the volume fraction of each solvent in the mixture.

\section{Differential scanning calorimetry analysis}

The DSC measurements were conducted using the DSC Q100 (TA Instrument) equipped with a refrigeration cooling system. A sample $(5.0-10.0 \mathrm{mg})$ was accurately weighed and placed in a crimped aluminium pan. All film samples were gently ground using a mortar and pestle to a fine powder under liquid nitrogen. Felodipine was heated to $200^{\circ} \mathrm{C}$ at a heating rate of $20^{\circ} \mathrm{C} / \mathrm{min}$. The $T_{\mathrm{g}}$ values of the solid dispersion films and polymer powder were obtained using a heat cool cycle by heating the samples from $0{ }^{\circ} \mathrm{C}$ to $200^{\circ} \mathrm{C}$ and left at this temperature for $15 \mathrm{~min}$ to eliminate the traces of moisture of the samples. Then the samples were cooled to $0{ }^{\circ} \mathrm{C}$ and heated again up to $200^{\circ} \mathrm{C}$. The heating and cooling rates were $20^{\circ} \mathrm{C} / \mathrm{min}$. The $T_{\mathrm{g}}$ value was the midpoint of the transition step in the second heating cycle.

\section{Dynamic mechanical analysis (DMA)}

The DMA experiments for PVP and felodipine/PVP films were measured using a Tritec 2000 DMA (Triton Technology Ltd., Nottinghamshire, UK) operating with a Tritec 2000 DMA version 1.43 .00 software. Since PVP with $10 \%$ felodipine films are too brittle for the DMA test, a powder pocket was used as previously described ${ }^{21}$. The PVP and felodipine/PVP films were cut into a rectangular shape and loaded into a metal pocket fabricated from a sheet of stainless steel. The pocket was then clamped directly into the instrument. One end of the pocket was clamped to the rigid frame while the other was attached to the moving driveshaft. The force data in the software depended on the experimental geometry which was a rectangular cross-section as previously described ${ }^{21}$. The pocket dimensions were measured using a ProMax electronic digital calliper (Fowler, USA) with a width, length, and thickness of $5.46 \mathrm{~mm}, 15.48 \mathrm{~mm}$, and $0.61 \mathrm{~mm}$, respectively. The pocket was subjected to a bending oscillatory motion in and out of the plane, forcing horizontal shearing of the film between the two plates of the pocket. The experimental parameters employed in this study were a dynamic displacement of $0.02 \mathrm{~mm}$ under a frequency of $1 \mathrm{~Hz}$, heating from $25^{\circ} \mathrm{C}$ to $250^{\circ} \mathrm{C}$ at a rate of $10^{\circ} \mathrm{C} / \mathrm{min}$.

\section{Powder X-ray diffraction (PXRD)}

PXRD of sample films were measured using a MiniFlex II Desktop X-ray diffractometer (Rigaku, Japan).
Monochromatic $\mathrm{CuK} \alpha$ radiation was obtained with Ni-filtration and a system of diverging, receiving, and scattering slides of $1.25^{\circ}, 0.3 \mathrm{~mm}$, and $1.25^{\circ}$, respectively. The diffraction pattern was measured with a voltage of $30 \mathrm{kV}$ and a current of $15 \mathrm{~mA}$ in the region of $4^{\circ}<2 \theta<90^{\circ}$ in a step scan mode of $2^{\circ}$ every second.

\section{Fourier transform infrared spectroscopy}

FTIR spectra were performed on a Fourier transform infrared spectrometer model 4100 (Jasco, Japan). All films were ground into a powder and prepared as $\mathrm{KBr}$ discs. To obtain an acceptable signal/noise ratio, 16 scans were acquired and the resolution was set at $4 \mathrm{~cm}^{-1}$. All spectra were operated using the JASCO SPECTRA MANAGER Version 2 software.

\section{Mechanical properties}

A TA.XT plus Texture Analyser equipped with a $5 \mathrm{~kg}$ load cell, TA-96 grips, and the TEXTURE EXPERT EXPONENT software Version 5.0 (Stable Micro Systems, UK) were used to determine the mechanical properties of the PVP and felodipine/PVP films. The film samples with a thickness of $0.103 \mathrm{~mm}$ were cut into $40 \mathrm{~mm}$ long and $5 \mathrm{~mm}$ wide strips. All samples which were free from physical imperfections were held between 2 grips. The distance between the grips was set at $30 \mathrm{~mm}$. The crosshead speed was set at $1 \mathrm{~mm} / \mathrm{s}$, and the data acquisition was ended when the film completely failed. Data from the samples that failed at the clamp, not between the clamps, were not used to determine the mechanical properties. Young's modulus, stress, and percent strain were acquired.

\section{RESULTS AND DISCUSSION}

Clear and smooth films were obtained from the PVP film without felodipine. Pale yellow-clear films were observed for the PVP film containing $10 \%$ felodipine. The average thickness of PVP K90 films were about $0.103 \mathrm{~mm}$. All films were kept at room temperature and protected from light for further tests.

\section{Solubility parameter of drug, polymer, and solvent}

Solubility parameters of felodipine, PVP, DM, E, and the binary mixtures of DM/E are listed in Table 1 . The solubility parameter of $\mathrm{DM} / \mathrm{E}$ at $5 / 5$ was most close to that of PVP.

\section{Differential scanning calorimetry (DSC)}

The thermogram of pure felodipine is shown in Fig. 2. The melting point of felodipine was observed at the first heating ramp at $148.39^{\circ} \mathrm{C}$ with onset at $143.47{ }^{\circ} \mathrm{C}$. The $T_{\mathrm{g}}$ value of felodipine observed at 
Table 1 Solubility parameters of felodipine, PVP, dichloromethane (DM), ethanol (E), and binary mixtures of $\mathrm{DM} / \mathrm{E}$.

\begin{tabular}{lc}
\hline Compound & Solubility \\
\hline $\mathrm{DM} / \mathrm{E}=0 / 1$ & 26.5 \\
$\mathrm{DM} / \mathrm{E}=1 / 9$ & 25.6 \\
$\mathrm{DM} / \mathrm{E}=3 / 7$ & 23.9 \\
$\mathrm{DM} / \mathrm{E}=5 / 5$ & 22.5 \\
$\mathrm{DM} / \mathrm{E}=7 / 3$ & 21.4 \\
$\mathrm{DM} / \mathrm{E}=9 / 1$ & 20.5 \\
$\mathrm{DM} / \mathrm{E}=1 / 0$ & 20.2 \\
$\mathrm{PVP}$ & 22.2 \\
Felodipine & 23.1 \\
\hline
\end{tabular}

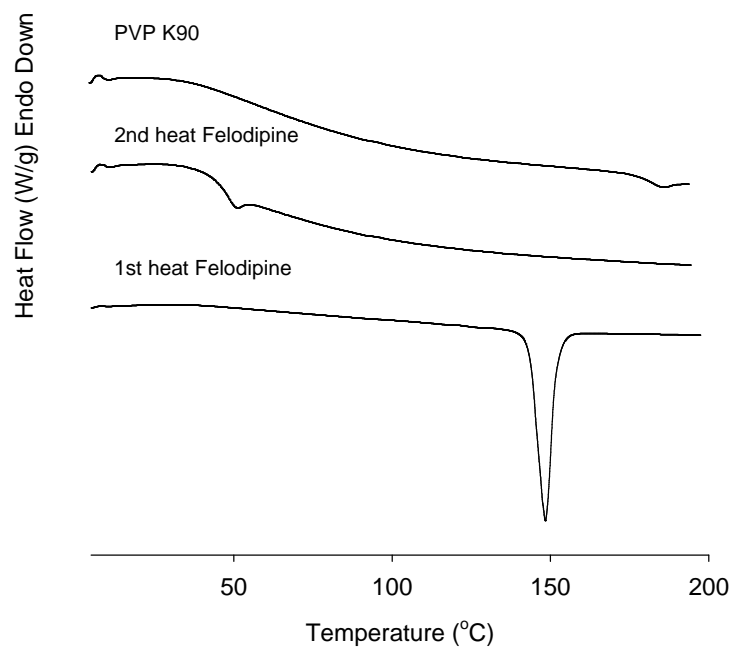

Fig. 2 The DSC thermograms of PVP and felodipine observed at the first and second heating ramp.

the second heating ramp was $48.56^{\circ} \mathrm{C}$. Furthermore, data obtained from the DSC study of felodipine corresponded to the polymorph form I of felodipine as previously reported ${ }^{22}$. The $T_{\mathrm{g}}$ value of the PVP powder was obtained from the second heating ramp at $182.58^{\circ} \mathrm{C}$ (Fig. 2). Both the $T_{\mathrm{g}}$ values of felodipine and PVP were used to calculate the $T_{\mathrm{g}}$ value for a binary mixture $\left(T_{\mathrm{g}, \text { mix }}\right)$ based on (3).

Generally, the $T_{\mathrm{g}, \text { mix }}$ can be calculated using the Couchman-Karasz equation ${ }^{23}$ :

$$
T_{\mathrm{g}, \text { mix }}=\frac{w_{1} T_{\mathrm{g} 1}+K w_{2} T_{\mathrm{g} 2}}{w_{1}+K w_{2}}
$$

where $T_{\mathrm{g} i}$ and $w_{i}$ are the $T_{\mathrm{g}}$ and weight fraction of component $i . K$ is a constant calculated using the change in heat capacities $\left(\Delta C_{\mathrm{p}}\right)$ at the $T_{\mathrm{g}}$ events for a
Table 2 Glass transition temperature $\left(T_{\mathrm{g}}\right)$ and Young's modulus of felodipine/PVP solid dispersions prepared using various ratios of dichloromethane (DM)/ethanol (E).

\begin{tabular}{lccc}
\hline $\begin{array}{l}\text { Solvent } \\
(\mathrm{DM} / \mathrm{E})\end{array}$ & $\begin{array}{c}T_{\mathrm{g}} \text { from } \\
\mathrm{DSC}\left({ }^{\circ} \mathrm{C}\right)\end{array}$ & $\begin{array}{c}T_{\mathrm{g}} \text { from } \\
\text { DMA }\left({ }^{\circ} \mathrm{C}\right)\end{array}$ & $\begin{array}{c}\text { Young's } \\
\text { modulus (MPa) }\end{array}$ \\
\hline $0 / 1$ & 142.0 & 155.7 & 0.573 \\
$1 / 9$ & 143.2 & 156.9 & 0.567 \\
$3 / 7$ & 142.8 & 154.8 & 0.582 \\
$5 / 5$ & 150.0 & 162.5 & 0.654 \\
$7 / 3$ & 148.0 & 156.0 & 0.592 \\
$9 / 1$ & 141.0 & 156.2 & 0.570 \\
$1 / 0$ & 138.5 & 143.3 & 0.570 \\
\hline
\end{tabular}

single component:

$$
K=\frac{\Delta C_{\mathrm{p} 2}}{\Delta C_{\mathrm{p} 1}}
$$

The measured $\Delta C_{\mathrm{p}}$ values were $0.44 \mathrm{~J} /(\mathrm{g} \mathrm{K})$ and $0.14 \mathrm{~J} /(\mathrm{g} \mathrm{K})$ for felodipine and PVP, respectively. Since Couchman-Karasz equation is not involved with the solvent used to prepare the mixture, all binary mixtures with the same proportion of PVP and felodipine (10\%) provided the same $T_{\mathrm{g}, \text { mix }}$ at $148.18^{\circ} \mathrm{C}$. Nevertheless, the $T_{\mathrm{g}, \text { mix }}$ predicted by Couchman-Karasz equation of a binary mixture was compared with the glass transition obtained from the DSC and DMA measurements.

According to the DSC measurement, the $T_{\mathrm{g}}$ of all felodipine/PVP films show only a single glass transition point, this may demonstrate that PVP and felodipine could be mixed at a molecular level or be dispersed as a nanodispersions. The values obtained from this study agree with other studies ${ }^{14,24,25}$. According to the DSC measurements, the $T_{\mathrm{g}}$ values for felodipine/PVP films (Table 2) are comparable to those calculated using the Couchman-Karasz equation $\left(148.18^{\circ} \mathrm{C}\right)$. In addition, the film prepared using a binary mixture of $\mathrm{DM} / \mathrm{E}$ at a $5 / 5$ volume ratio exhibited the highest $T_{\mathrm{g}}$ value of $150.0^{\circ} \mathrm{C}$ (Fig. 3). Actually, a solvent can affect the molecular shape or mobility of a polymer. The mixture of DM/E at 5/5 may be a good solvent for this system. It may be able to promote chain elongation and increase the molecular surface of PVP resulting in an enhancement of the interaction between felodipine and PVP. Felodipine could form strong hydrogen bonds with PVP that would increase the polymer chain network rigidity of the films when the solvent was evaporated, resulting in a high $T_{\mathrm{g}}$ value. 


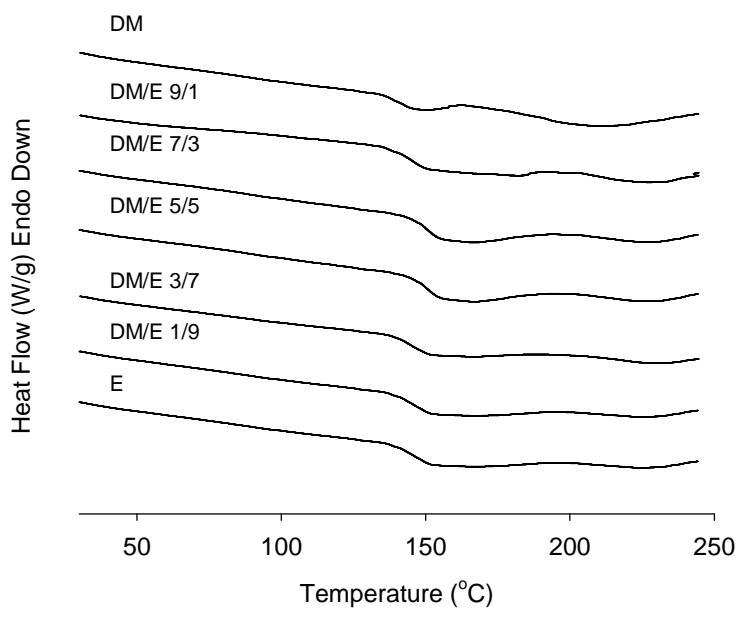

Fig. 3 The DSC thermograms showing the glass transitions of felodipine/PVP solid dispersion films prepared using various ratios of dichloromethane (DM)/ethanol (E).

\section{Dynamic mechanical analysis}

The elastic response of samples is represented by the storage or tensile modulus $\left(E^{\prime}\right)$ while the loss modulus $\left(E^{\prime \prime}\right)$ is the viscous response. The tangent of the loss angle or the mechanical loss $(\tan \delta)$ was equal to the ratio of the lost modulus to the storage modulus ${ }^{26}$ :

$$
\tan \delta=\frac{\text { loss modulus }}{\text { storage modulus }}=\frac{E^{\prime \prime}}{E^{\prime}}
$$

This equation applies for the response of material changes with temperature at a fixed frequency. The profiles of the elastic component of the $E^{\prime}$ and the $\tan \delta$ with respect to temperature were obtained directly from DMA. The glass transition point can be described as a conversion of the polymer from a glass-like state, in which there is a restricted motion of the polymeric chains, to a rubber-like state in which there is a loss in rigidity (i.e., increased relaxation) associated with an enhanced polymeric chain mobility ${ }^{27}$. DMA is also a very sensitive technique for characterizing the glass transition. Typically, the glass transition is defined as a decrease in $E^{\prime}$, caused by the decrease in the resistance of the material to deformation. This glass transition can also be determined from a peak in the damping component $(\tan \delta)$ due to the increased loss of energy as heat during the transition process $^{21}$. In this study, DMA was employed to determine the glass transition of the film samples.

The powder pocket DMA response for the felodipine/PVP films is shown in Fig. 4. The $T_{\mathrm{g}}$ values for the films are listed in Table 2 . The $T_{\mathrm{g}}$ value obtained from the film prepared using DM/E at a 5/5

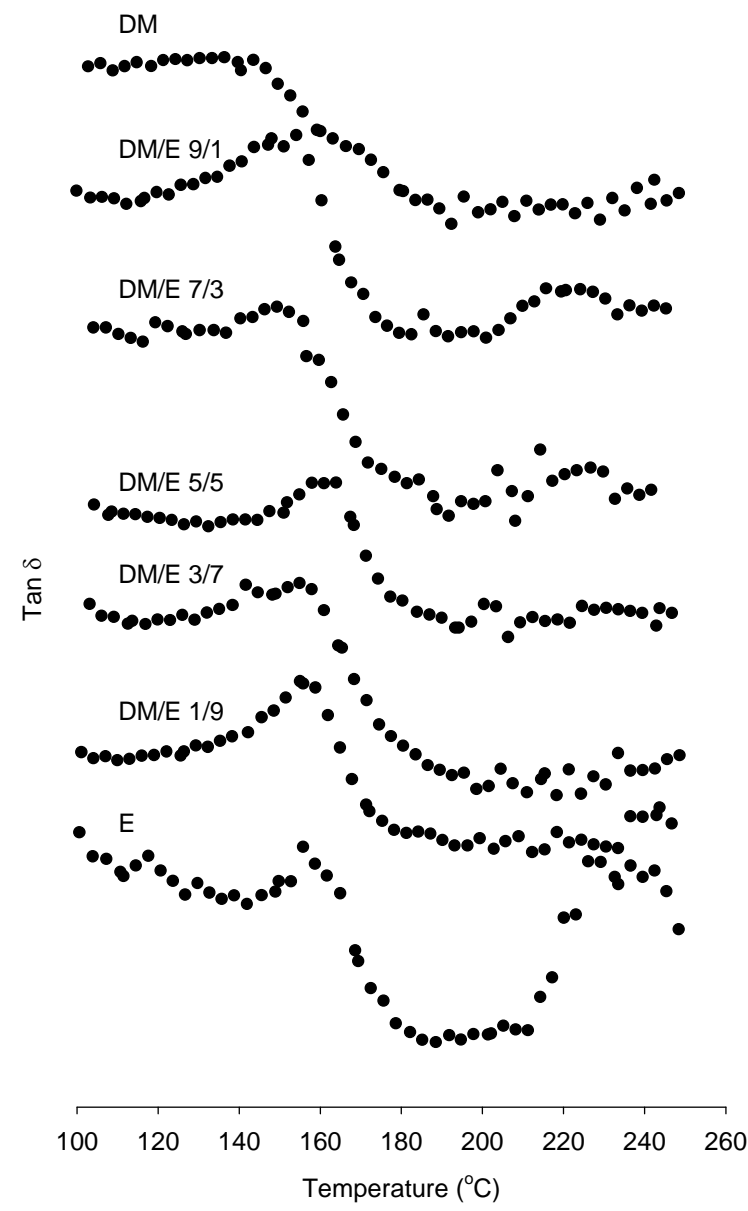

Fig. 4 A powder pocket DMA response for the felodipine/PVP solid dispersion films prepared using various ratios of dichloromethane (DM)/ethanol (E).

volume ratio showed the highest value compared to the films prepared with other DM/E ratios. The high $T_{\mathrm{g}}$ value demonstrated that the system required a high activation energy for the relaxation process and the transition from the glassy state to the rubbery state ${ }^{13}$. This was due to the strong interaction between the polymer chain and felodipine. These DMA experiments were consistent with those obtained from the DSC measurements.

\section{Mechanical properties}

The TEXTURE EXPERT EXPONENT software was used to generate the stress-strain curves and to calculate the tensile strength and percentage strain. The tensile strength is defined as the maximum stress $\left(\sigma_{\max }\right)$ sustained by the material and was calculated as the ratio of the maximum force applied during a tension test carried to break point $\left(F_{\max }\right)$ and the 
original cross sectional area of the sample $(A)^{28}$ :

$$
\text { stress }=\sigma_{\max }=\frac{F_{\max }}{A}
$$

The elongation at the break (strain) was calculated from the ratio of the change in the length $(\Delta L)$ of the sample to its original length $(L)$ :

$$
\text { strain }=\frac{\Delta L}{L}
$$

Young's modulus was calculated from the slope of the initial linear part of the stress-strain curve and expressed in MPa:

$$
\text { Young's modulus }=\frac{\text { stress }}{\text { strain }}
$$

Young's modulus of felodipine/PVP films were calculated and listed in Table 2. Young's modulus of felodipine/PVP films prepared using a binary mixture of $\mathrm{DM} / \mathrm{E}$ at a $5 / 5$ volume ratio was the highest and can be related to the rigidity of the material due to the high interaction between the felodipine molecules and the polymer chain. A good correlation was observed between the $T_{\mathrm{g}}$ values obtained using DSC and DMA as well as Young's modulus values obtained from the texture analyser. The best solvent for the preparation of felodipine/PVP solid dispersion is a binary mixture of $\mathrm{DM} / \mathrm{E}$ at a $5 / 5$ volume ratio.

\section{Powder X-ray diffraction (PXRD)}

The PXRD pattern of the crystalline felodipine and the felodipine/PVP films is shown in Fig. 5. No peak was observed for the PXRD for any felodipine/PVP film. This demonstrated that felodipine in all solid dispersion films was in an amorphous state. Moreover, felodipine in these films still remained in an amorphous form after two months of preparation. The film prepared using DM/E at a $5 / 5$ volume ratio showed better stability than the others with little change of its amorphous halo shape after 2 months. The films prepared using other DM/E ratios showed some changes of the PXRD pattern, i.e., a change from one halo peak to two halo peaks or an increase of the halo peaks (Fig. 5).

\section{Fourier transform infrared spectroscopy}

Felodipine showed prominent bands of an amine $(\mathrm{N}-\mathrm{H})$ and ester carbonyl $(\mathrm{C}=\mathrm{O})$ group at 3370 and $1698 \mathrm{~cm}^{-1}$, respectively (Fig. 6). The FTIR spectrum of PVP exhibited a characteristic peak of $\mathrm{C}=\mathrm{O}$ stretching at the wavenumber of $1667 \mathrm{~cm}^{-1}$, and for a $\mathrm{C}-\mathrm{N}$ stretching peak at $1288 \mathrm{~cm}^{-1}$. A
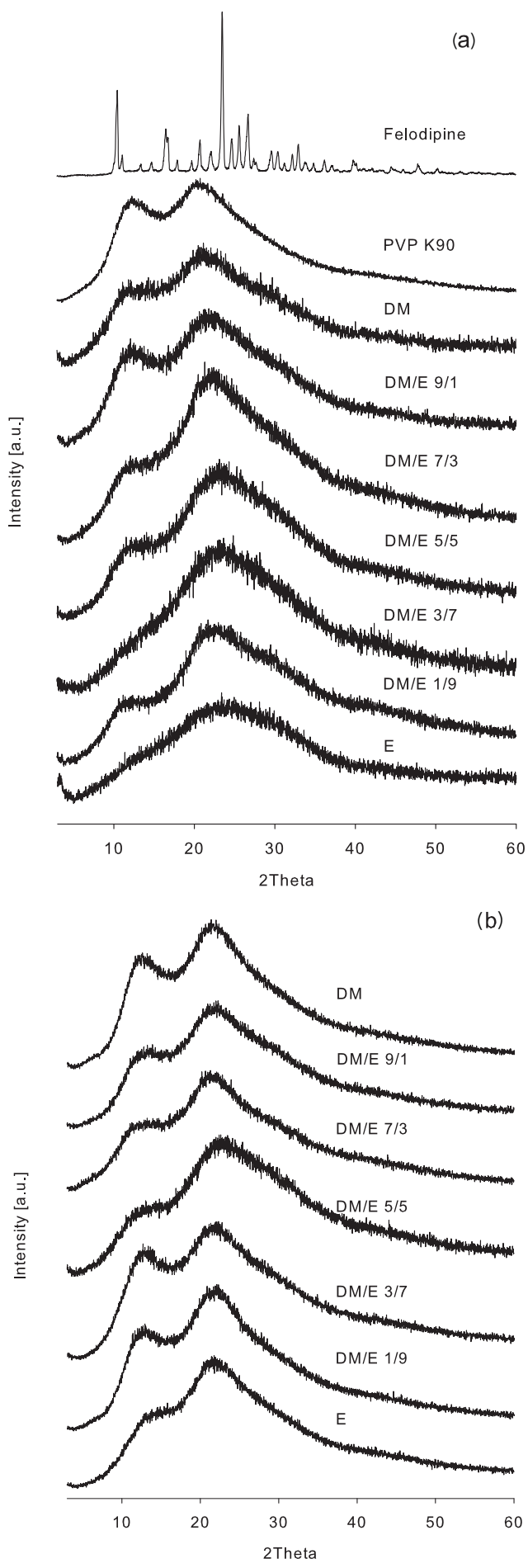

Fig. 5 PXRD analysis of felodipine, PVP, and felodipine/PVP solid dispersion films prepared using various ratios of dichloromethane (DM)/ethanol (E) at (a) day 1 and (b) 8 weeks. 

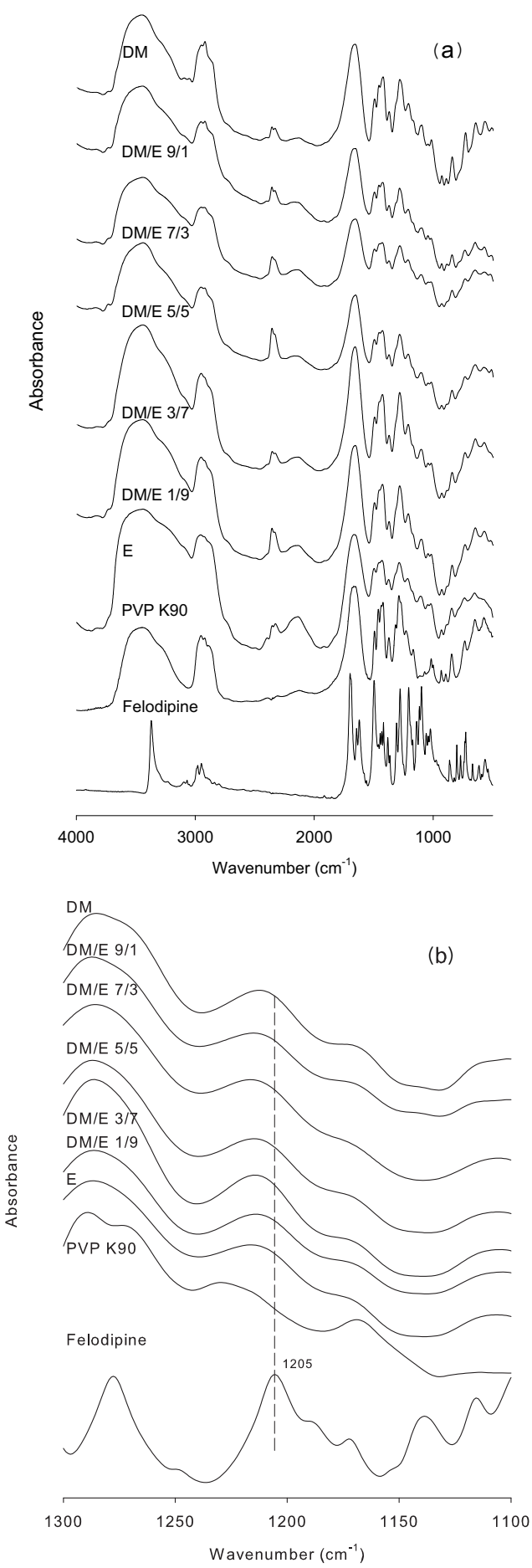

Fig. 6 Infrared spectra of PVP, felodipine, and felodipine/PVP solid dispersion film prepared using various ratios of dichloromethane (DM)/ethanol (E), (a) the whole range spectra and (b) the expanded spectra over the range of 1300 $1100 \mathrm{~cm}^{-1}$. shift of the $\mathrm{C}=\mathrm{O}$ band of PVP in the felodipine/PVP film was not observed (Fig. 6a). This was probably due to the high proportion of PVP (90\%) compared to felodipine $(10 \%)$. Due to the hydrophilic nature of PVP, the broad $\mathrm{OH}$ band was detected at about $3500 \mathrm{~cm}^{-1}$. These $\mathrm{OH}$ bands were also clearly observed in felodipine/PVP films and they covered the $\mathrm{N}-\mathrm{H}$ bands of felodipine. Thus it is impossible to detect the shift of the $\mathrm{N}-\mathrm{H}$ band of felodipine in the solid dispersion films. Hence it was not possible to identify the interacting group of felodipine with PVP from this $\mathrm{N}-\mathrm{H}$ band. However, a shift of the $\mathrm{C}-\mathrm{N}$ peak at $1205 \mathrm{~cm}^{-1}$ for felodipine to the higher wavenumber was detected (Fig. 6b). The detection of this peak shift was possible since PVP did not show any peak in this region. This shift provides some evidence that there was a hydrogen bond interaction between the $\mathrm{N}-\mathrm{H}$ group of felodipine and the proton acceptor of the $\mathrm{C}=\mathrm{O}$ group of PVP. Furthermore, the interaction between these two molecules may occur (Fig. 1).

\section{CONCLUSIONS}

This study demonstrates the impact of the solvents on the solid dispersion properties when prepared by the solvent evaporation methods. Felodipine in all felodipine/PVP solid dispersion films was in an amorphous state. Hydrogen bonding interactions play an important role in the physical stability of the drug and the interactions were confirmed using FTIR analyses. The highest $T_{\mathrm{g}}$ and Young's modulus were observed in a felodipine/PVP film prepared using a binary mixture of $\mathrm{DM} / \mathrm{E}$ at $5 / 5$ volume ratio. This solvent system can enhance PVP chain elongation, increase the interactions of the drug and the polymer, and result in the high rigidity of the polymer chain that was demonstrated as an increase in the $T_{\mathrm{g}}$ and Young's modulus values. Thus this solvent system can be classified as a good solvent for the solid dispersion of the PVP system.

Acknowledgements: This work was supported by the Thailand Research Fund through the Royal Golden Jubilee Ph.D. Programme (PHD/0170/2547) to KS.

\section{REFERENCES}

1. Serajuddin AT (1999) Solid dispersion of poorly water-soluble drugs: early promises, subsequent problems, and recent breakthroughs. J Pharmaceut Sci 88, 1058-66.

2. Dressman J, Reppas C (2007) Drug solubility: how to measure it, how to improve it. Adv Drug Deliv Rev 59, 531-2. 
3. Law D, Krill SL, Schmitt EA, Fort JJ, Qiu Y, Wang W, Porter WR (2001) Physicochemical considerations in the preparation of amorphous ritonavir-poly(ethylene glycol) 8000 solid dispersions. J Pharmaceut Sci 90, 1015-25.

4. Leuner C, Dressman J (2000) Improving drug solubility for oral delivery using solid dispersions. Eur J Pharm Biopharm 50, 47-60.

5. Sekikawa H, Nakano M, Arita $T$ (1978) Inhibitory Effect of Polyvinylpyrrolidone on the Crystallization of Drugs. Chem Pharmaceut Bull 26, 118-26.

6. Crowley KJ, Zografi G (2003) The effect of low concentrations of molecularly dispersed poly(vinylpyrrolidone) on indomethacin crystallization from the amorphous state. Pharmaceut Res 20, 1417-22.

7. Taylor LS, Zografi G (1997) Spectroscopic characterization of interactions between pvp and indomethacin in amorphous molecular dispersions. Pharmaceut Res 14 1691-8.

8. Miyazaki T, Yoshioka S, Aso Y, Kojima S (2004) Ability of polyvinylpyrrolidone and polyacrylic acid to inhibit the crystallization of amorphous acetaminophen. J Pharmaceut Sci 93, 2710-7.

9. Paudel A, Humbeeck JV, Mooter GVd (2010) Theoretical and experimental investigation on the solid solubility and miscibility of naproxen in poly(vinylpyrrolidone). Mol Pharm 7, 1133-48.

10. Greenhalgh DJ, Williams AC, Timmins P, York P (1999) Solubility parameters as predictors of miscibility in solid dispersions. J Pharmaceut Sci 88, 1182-90.

11. Nair R, Nyamweya N, Gönen S, Martínez-Miranda LJ, Hoag SW (2001) Influence of various drugs on the glass transition temperature of poly(vinylpyrrolidone): a thermodynamic and spectroscopic investigation. Int $J$ Pharm 225, 83-96.

12. Chiou WL, Riegelman S (1971) Pharmaceutical applications of solid dispersion systems. J Pharmaceut Sci 60, 1281-302.

13. Al-Obaidi H, Brocchini S, Buckton G (2009) Anomalous Properties of Spray Dried Solid Dispersions. J Pharmaceut Sci 98, 4724-37.

14. Konno H, Taylor L (2008) Ability of different polymers to inhibit the crystallization of amorphous felodipine in the presence of moisture. Pharmaceut Res 25, 969-78.

15. Kim E-J, Chun M-K, Jang J-S, Lee I-H, Lee K-R, Choi H-K (2006) Preparation of a solid dispersion of felodipine using a solvent wetting method. Eur $J$ Pharm Biopharm 64, 200-5.

16. Karavas E, Ktistis G, Xenakis A, Georgarakis E (2005) Miscibility behavior and formation mechanism of stabilized felodipine-polyvinylpyrrolidone amorphous solid dispersions. Drug Dev Ind Pharm 31, 473-89.

17. Jones DS, Medlicott NJ (1995) Casting solvent controlled release of chlorhexidine from ethylcellulose films prepared by solvent evaporation. Int J Pharm 114, 257-61.
18. Hansen CM (1969) The universality of the solubility parameter. Ind Eng Chem Prod Res Dev 8, 2-11.

19. Archer WL (1991) Determination of hansen solubility parameters for selected cellulose ether derivatives. Ind Eng Chem Res 30, 2292-8.

20. Archer WL (1992) Hansen solubility parameters for selected cellulose ether derivatives and their use in the pharmaceutical industry. Drug Dev Ind Pharm 18, 599-616.

21. Royall PG, Huang CY, Tang SW, Duncan J, Van-deVelde G, Brown MB (2005) The development of DMA for the detection of amorphous content in pharmaceutical powdered materials. Int J Pharm 301, 181-91.

22. Rollinger JM, Burger A (2001) Polymorphism of racemic felodipine and the unusual series of solid solutions in the binary system of its enantiomers. J Pharmaceut Sci 90, 949-59.

23. Couchman PR, Karasz FE (1978) A classical thermodynamic discussion of the effect of composition on glass-transition temperatures. Macromolecules 11, 117-9.

24. Konno H, Taylor L (2006) Influence of different polymers on the crystallization tendency of molecularly dispersed amorphous felodipine. J Pharmaceut Sci 95, 2692-705.

25. Marsac P, Konno H, Rumondor A, Taylor L (2008) Recrystallization of nifedipine and felodipine from amorphous molecular level solid dispersions containing poly (vinylpyrrolidone) and sorbed water. Pharmaceut Res 25, 647-56.

26. Honary S, Orafai H (2002) The effect of different plasticizer molecular weights and concentrations on mechanical and thermomechanical properties of free films. Drug Dev Ind Pharm 28, 711-5.

27. Jones DS (1999) Dynamic mechanical analysis of polymeric systems of pharmaceutical and biomedical significance. Int J Pharm 179, 167-78.

28. Prodduturi S, Urman KL, Otaigbe JU, Repka MA (2007) Stabilization of hot-melt extrusion formulations containing solid solutions using polymer blends. AAPS PharmSciTech 8, E152-61. 